\title{
Orthorectification of KOMPSAT Optical Images Using Various Ground Reference Data and Accuracy Assessment
}

\author{
Kwangjae Lee, Eunseon Kim, and Younsoo Kim \\ National Satellite Operation \& Application Center, Korea Aerospace Research Institute, 169-84 Gwahak-ro, Yuseong-gu, \\ Daejeon 34133, Republic of Korea \\ Correspondence should be addressed to Kwangjae Lee; kjlee@kari.re.kr
}

Received 26 April 2017; Accepted 19 June 2017; Published 8 August 2017

Academic Editor: Saro Lee

Copyright (C) 2017 Kwangjae Lee et al. This is an open access article distributed under the Creative Commons Attribution License, which permits unrestricted use, distribution, and reproduction in any medium, provided the original work is properly cited.

\begin{abstract}
Along with the appearance of high resolution satellite images, image correction using Rational Polynomial Coefficients (RPCs) has become common. Location accuracy of Korea Multipurpose Satellite (KOMPSAT) standard images is still not adequate, so, in order to leverage the KOMPSAT images for applications such as mapping and change detection, it is necessary to orthorectify the images. In this study, using updated RPCs, we performed orthorectification of KOMPSAT-2, KOMPSAT-3, and KOMPSAT-3A images using various data. Through this study, we discovered that the orthorectification result using precise Ground Control Points (GCPs) and Digital Elevation Model (DEM) is the best, but it was found that the correction results through image matching are also excellent. In particular, it was confirmed that orthoimages with a planimetric accuracy around $3 \mathrm{~m}$ (Root Mean Square Error (RMSE)) can be generated by using well-known matching algorithms with open data such as OpenStreetMap (OSM) and Shuttle Radar Topography Mission (SRTM) DEM, which can be acquired by anyone. Although the accuracy was low in some mountainous terrain, it was confirmed that it could be used for generating KOMPSAT orthoimages using open data. This paper describes the results for orthorectifying high resolution KOMPSAT optical images using various reference data.
\end{abstract}

\section{Introduction}

Over the past several decades, various images from earth observation satellites have been used to monitor geographical events ranging from global disasters to climate and environmental changes. Due to the rapid development of satellite technology, the application range of satellite images is continuously expanding. In particular, high resolution images from low-orbit satellites are being used in applications from change detection to cause analysis. Low-orbit satellite images are widely used for generating various thematic maps based on high spatial resolution, even though the observation width is narrow. In the past, traditional mapping was performed based on aerial photographs, but in recent years, high resolution satellite images have been widely used in the field of cartography. However, high location accuracy is required to utilize satellite images for mapping and precise change detection.

Since most satellite images received cannot be used immediately, an additional processing step must be performed.
The most basic postprocessing at the user level is geometric correction. The geometric correction of satellite images is an important step to improve data utilization. For example, in order to detect a change between two images, basic position matching between images should be performed. A typical way to correct for geometric distortion effects is to use Ground Control Points (GCPs). However, the problem with this type of correction is that it requires many in situ field measurements. In general, GCPs for high resolution satellite image correction can be obtained from GPS survey or precise reference data, but there are restrictions on obtaining a large number of GCPs in this manner. Ideally, a model that utilizes GCPs is the most accurate in terms of geometric correction.

Along with the appearance of high resolution satellite images, sensor modeling has been a very important research theme in photogrammetry. The technology related to mapping started to develop rapidly with the launch of SPOT-1 in 1986 [1]. In the past, physical sensor models were widely used for correcting push-broom satellite images, but the Rational 
TABLE 1: Main specifications of KOMPSAT.

\begin{tabular}{lccc}
\hline Items & KOMPSAT-2 & KOMPSAT-3 & KOMPSAT-3A \\
\hline Ground Sample Distance (GSD) & PAN: $1 \mathrm{~m} @$ nadir & PAN: $0.7 \mathrm{~m} @$ nadir & PAN: 0.55 m @ nadir \\
& MS: $4 \mathrm{~m} @$ nadir & MS: $2.8 \mathrm{~m} @$ nadir & MS: $2.2 \mathrm{~m} @$ nadir \\
& PAN: $500 \sim 900 \mathrm{~nm}$ & PAN: $450 \sim 900 \mathrm{~nm}$ & PAN: $400 \sim 900 \mathrm{~nm}$ \\
Spectral band & MS1 (Blue): $450 \sim 520 \mathrm{~nm}$ & MS1 (Blue): $450 \sim 520 \mathrm{~nm}$ & MS1 (Blue): $450 \sim 520 \mathrm{~nm}$ \\
& MS2 (Green): $520 \sim 600 \mathrm{~nm}$ & MS2 (Green): $520 \sim 600 \mathrm{~nm}$ & MS2 (Green): $520 \sim 600 \mathrm{~nm}$ \\
Swath width & MS3 (Red): $630 \sim 690 \mathrm{~nm}$ & MS3 (Red): $630 \sim 690 \mathrm{~nm}$ & MS3 (Red): 630 690 nm \\
Altitude & MS4 (NIR): $760 \sim 900 \mathrm{~nm}$ & MS4 (NIR): $760 \sim 900 \mathrm{~nm}$ & MS4 (NIR): 760 900 nm \\
Quantization & $15 \mathrm{~km} @$ nadir & $16 \mathrm{~km} @$ nadir & $13 \mathrm{~km} @$ nadir \\
Duty cycle & $685 \mathrm{~km}$ & $685 \mathrm{~km}$ & $528 \mathrm{~km}$ \\
\hline
\end{tabular}

Function Model (RFM) with Rational Polynomial Coefficients (RPCs) is now commonly used with high resolution satellite images. RFM has been the most popular geometric correction method for orthorectifying high resolution images. RPCs provide a compact representation of groundto-image geometry, allowing photogrammetric processing without requiring a physical camera model. However, since RPCs are generated by satellite orbital information and a camera model, they contain various biases from the satellite. Therefore, in order to generate a precise map based on high location accuracy, it is necessary to eliminate such bias. Many methods for RPC refinement have been proposed in order to improve location accuracy of high resolution satellite images [2-8].

Currently, the Korea Aerospace Research Institute (KARI) offers a variety of optical images from the Korea Multipurpose Satellite (KOMPSAT) series. The location accuracy of KOMPSAT-2 on the system level is $80 \mathrm{~m}$ (CE90, or Circular Error of $90 \%$ ). The average horizontal location accuracy of KOMPSAT-2 standard images from 2007 to early 2009 was about $38 \mathrm{~m}$ (CE90) [9], but it was possible to improve location accuracy using GCPs $[10,11]$. Similarly, with KOMPSAT-3 and KOMPSAT-3A, the location accuracy of standard images without GCPs is $70 \mathrm{~m}$ (CE90), but this accuracy can be improved by using ground reference data [12-14]. KOMPSAT images featuring high location accuracy by postprocessing can be used very efficiently in the production of various thematic maps. However, as mentioned above, improving location accuracy through postprocessing requires reference materials, and it is not always possible to obtain high quality datasets. Furthermore, there is a need for a more efficient way to process large amounts of image data. Therefore, it is required to study methods to improve the location accuracy of KOMPSAT standard images based on various ground reference data. In this study, we performed an experiment for orthorectifying KOMPSAT optical images using various ground reference datasets and analyzed the accuracy difference according to the reference data.

\section{The Korea Multipurpose Satellite}

Various satellites have been developed by KARI in accordance with Korea's mid- to long-term plans for space development.
The KOMPSAT program has been carried out to meet the national demand for high resolution satellite imagery and to acquire advanced satellite technology.

KOMPSAT-1 operated remarkably well for 8 years in its sun-synchronous orbit after its successful launch on December 21, 1999. There were three sensors in KOMPSAT1, its main sensor being an Electrooptical Camera (EOC) to observe the land. The spatial resolution of the EOC was $6.6 \mathrm{~m}$ and it provided only panchromatic images. In February 2008, KOMPSAT-1 ceased operations.

Table 1 describes the main specifications for KOMPSAT to be used in this study. KOMPSAT-2 was the first high resolution satellite in Korea and has been operating normally since its launch on July 28, 2006. The Multispectral Camera (MSC), the on-board camera of KOMPSAT-2, provides a $1 \mathrm{~m}$ panchromatic image and a $4 \mathrm{~m}$ multispectral image with four bands in the nadir viewing condition. The swath width is $15 \mathrm{~km}$ at the nominal altitude of $685 \mathrm{~km}$. KOMPSAT-2 operates with a local time of ascending node of 10:50 a.m. Up to now, KOMPSAT-2 has been widely used for generating geospatial information and various thematic maps based on high spatial resolution [15].

KOMPSAT-3 was launched on May 18, 2012, as a followon to KOMPSAT-2. The mission objectives of KOMPSAT-3 are to provide continuous earth observation after KOMPSAT2 and to meet the nation's need for high resolution optical images required for the Geographic Information System (GIS) and other land, environmental, agricultural, and oceanographic monitoring applications. The mission altitude of KOMPSAT-3 is $685 \mathrm{~km}$. Local time of ascending nodes is 13:30 a.m. At the nominal mission altitude with nadir pointing, an Advanced Earth Imaging Sensor System (AEISS) provides $0.7 \mathrm{~m}$ panchromatic and $2.8 \mathrm{~m}$ multispectral images taken at a width of $16 \mathrm{~km}$. Unlike KOMPSAT-2, KOMPSAT3 has various imaging modes such as single pass stereo imaging, multipoint imaging, and wide area imaging.

KOMPSAT-3A, which is very similar to KOMPSAT-3, was launched on March 25, 2015. KOMPSAT-3A was developed to provide higher-resolution images by lowering the altitude to $528 \mathrm{~km}$. The AEISS-A, the main camera of KOMPSAT-3A, provides $0.55 \mathrm{~m}$ panchromatic image and $2.2 \mathrm{~m}$ multispectral image. KOMPSAT-3A also has a camera for midinfrared imaging with a spatial resolution of $5.5 \mathrm{~m}$. 


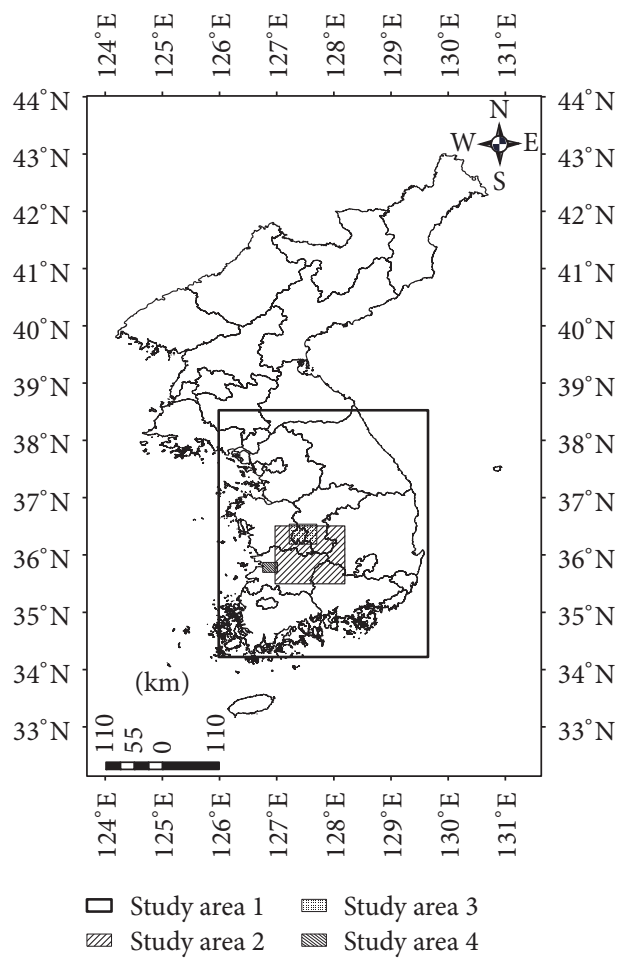

FIgURE 1: Location of the study areas.

There is also KOMPSAT-5 which provides Synthetic Aperture Radar (SAR) images, but we will not discuss it in this study.

\section{Materials and Methods}

3.1. Study Area. In this study, the study area is different according to the usage data, and the image processing experiment was performed on four regions of South Korea. In order to analyze the effect of the reference point and Digital Elevation Model (DEM) type on the orthorectification, the study area was selected by subdividing into the wide area, urban area, and rural area.

Figure 1 shows the total area of this study. Study area 1 is about $100,000 \mathrm{~km}^{2}$. In South Korea, about $63 \%$ of the entire country is forest, so there are not many plains. In addition, Korea is geographically surrounded by the sea, with about 2,900 islands distributed in the West Sea and the South Sea. The experiment for orthorectifying the KOMPSAT-2 images using general GCPs was performed in study area 1. Next, an orthorectification using GCP chips, which was made in the form of an image chip, was carried out on the southern part of the Korean peninsula where urban, forest, river, and farmland are distributed evenly. As shown in Figure 1, study area 2 covers five provinces, with a total area of approximately $9,400 \mathrm{~km}^{2}$. Study area 3 is Daejeon city, one of the major metropolitan areas in Korea. We conducted an experiment to analyze the influence of the ground reference data on the image correction in study area 3 . The last study area is a rural area located on the southwest side of the peninsula as shown in Figure 1. Here we analyzed the orthoimage accuracy of the KOMPSAT optical images.

3.2. Datasets. A variety of data was used to perform the KOMPSAT image correction experiments for a wide range of study areas. The data used in the study can be divided into the KOMPSAT images and ground reference data. In the case of the KOMPSAT images, which are the most important data in this study, images from KOMPSAT-2, KOMPSAT3 , and KOMPSAT-3A, the satellites which are currently in operation, were all used. Figure 2 shows the different types of KOMPSAT images used in the study. First, 947 images of KOMPSAT level 1R, which were acquired from 2007 to 2014, were selected as shown in Figure 2(a). In Figure 2(b), 50 images of KOMPSAT-2 were used for the image correction experiments based on GCP chips. The KOMPSAT-3 and KOMPSAT-3A images represented in Figures 2(c) and 2(d) were used to analyze the orthorectification results by various ground reference data.

Ground reference data is a very important factor in improving the location accuracy of a satellite image. The ground reference data used in this study were divided into DEM and GCPs. A DEM is needed to process a georeferenced satellite image to remove planar distortions caused by variations in terrain. Two types of DEMs were used. First, the DEM for the whole South Korean region was generated using digital topographic maps of 1:5000 scale which was created by the National Geographic Information Institute (NGII) in Korea. The result of analyzing the vertical $(z)$ accuracy using 318 checkpoints obtained from the Global Positioning System (GPS) survey was about $1.66 \mathrm{~m}$ (RMSE, Root Mean Square Error). The second DEM was obtained from the Shuttle Radar Topography Mission (SRTM) which filled a void in the data at a resolution of 1 arc second $(30 \mathrm{~m})$. In general, the SRTM DEM is renowned for its consistency and overall accuracy at the global scale [16]. However, the vertical accuracy of the SRTM DEM depends on the land cover [17]. Due to the characteristics of the SRTM C-band, the accuracy of SRTM height from a low vegetation area is much better than the SRTM mission specification. A total of 318 checkpoints were used to evaluate the accuracy of the SRTM DEM used in this study. As a result, the vertical accuracy was $5.17 \mathrm{~m}$ (RMSE).

The GCPs for orthorectification of the KOMPSAT images were extracted and used from aerial orthophotos that had a spatial resolution of $0.25 \mathrm{~m}$ and a horizontal accuracy of less than $1 \mathrm{~m}$ (RMSE). We also used GCP chips, which were extracted every $3 \mathrm{~km}$ from precisely corrected $1 \mathrm{~m}$ panchromatic images. GCP chips with horizontal $(x, y)$ and elevation $(z)$ information were created around South Korea, and the size of the chip is $128 \times 128$ pixels. OpenStreetMap (OSM) was used to analyze the possibility for orthorectification using open source data. In recent years, OSM has become the most popular open source data. Since OSM data can be modified by anyone, the location accuracy is different for each region. Therefore, before using this source, we performed an accuracy evaluation on some OSM sample data for both domestic and overseas regions. Figure 3 shows the results of overlapping a pair of OSM images with a 1:5000scale digital topographic map and a Google Earth image 


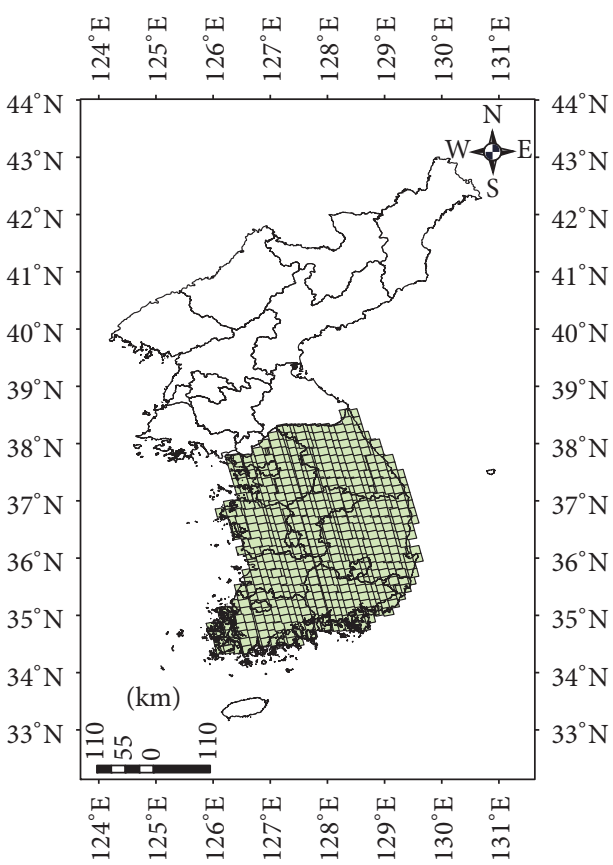

(a)

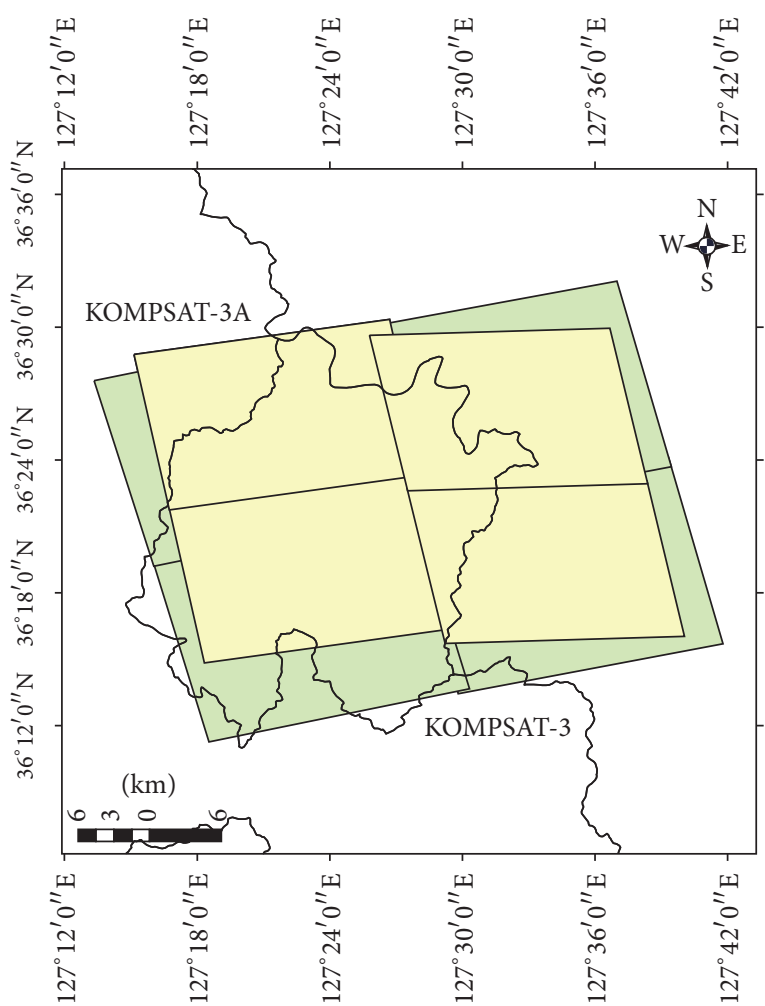

(c)

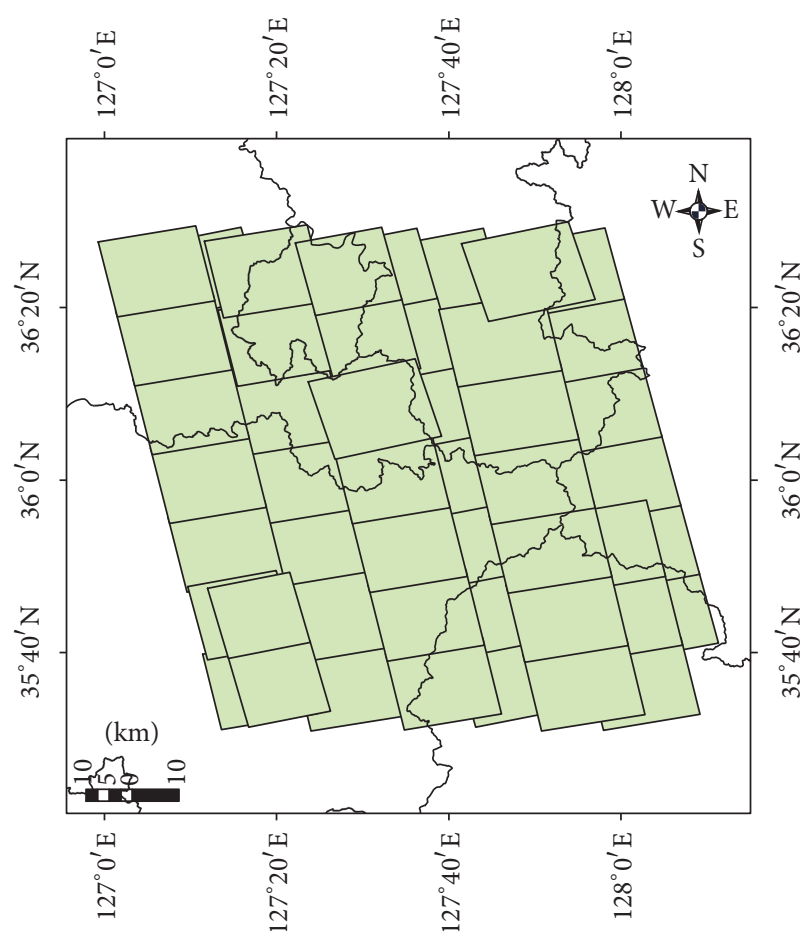

(b)

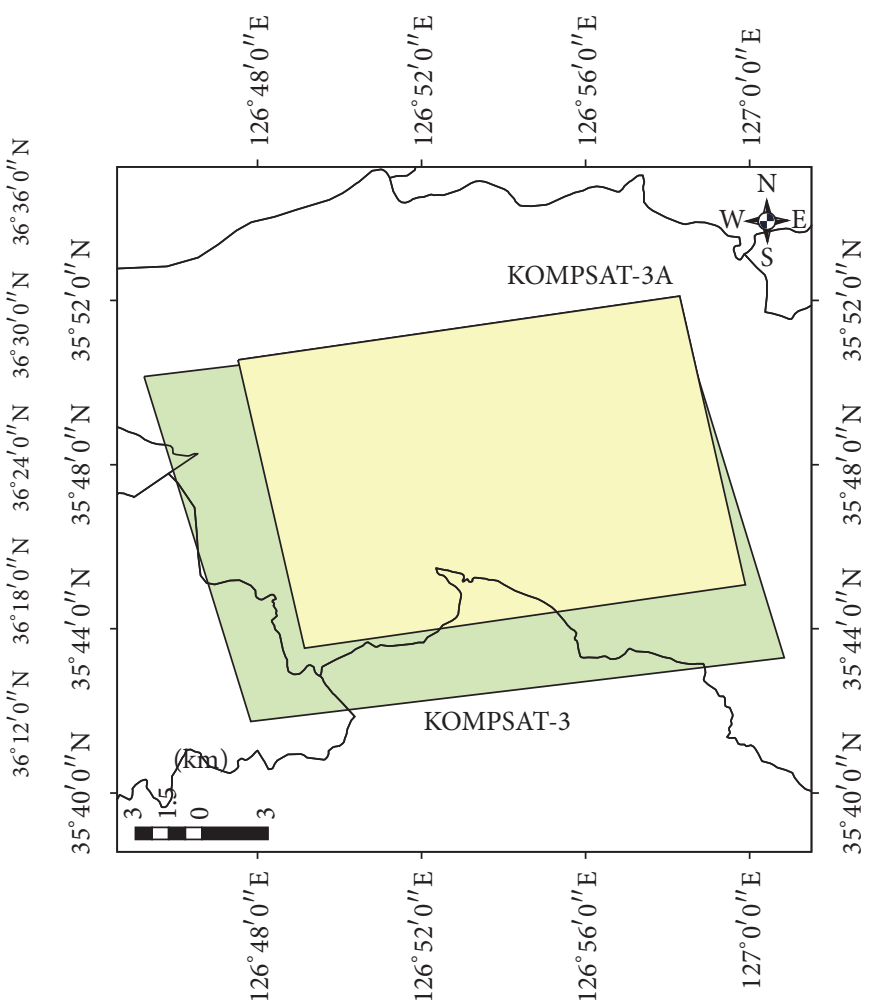

(d)

FIgURE 2: Image index of the study areas.

to easily evaluate the location accuracy of OSM data by visual inspection. The standard horizontal accuracy for the digital topographic map of $1: 5000$ scale is $\pm 3.5 \mathrm{~m}$, while the expected accuracy is less than $\pm 2.0 \mathrm{~m}$ [18]. In general, NGII produced a digital topographic map of 1:5000 scale through aerial photogrammetry based on the aerial photos of about $10 \sim 20 \mathrm{~cm}$. The Google Earth image of Napa Valley, USA, has a very high resolution of several centimeters. As shown in 


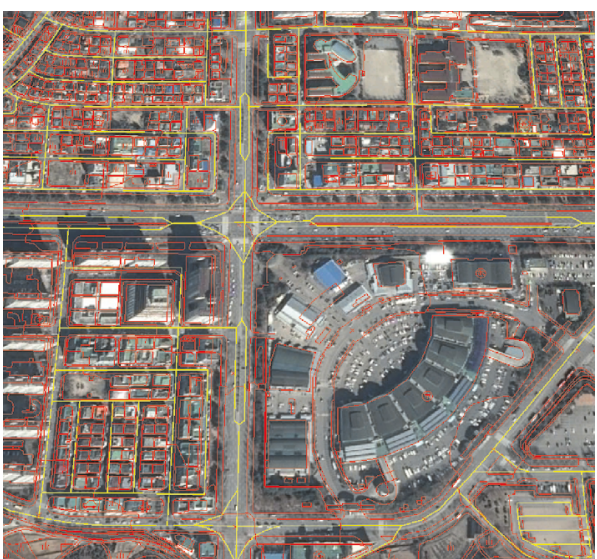

(a)

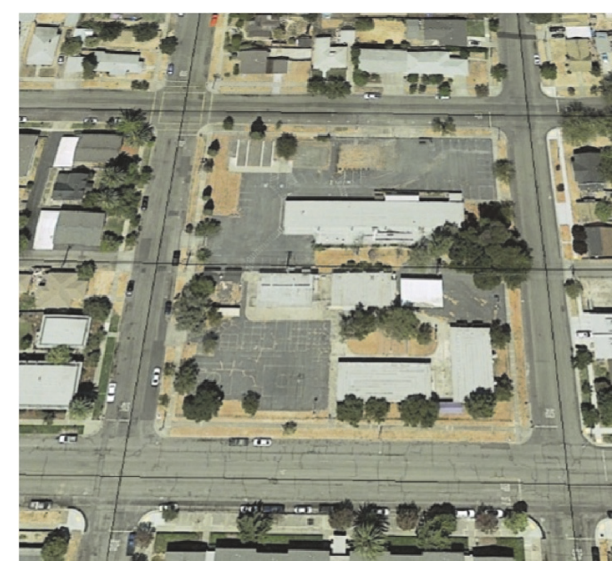

(b)

FIGURE 3: OSM data overlap results ((a) overlap of OSM (yellow line) and digital topographic map of 1:5000 scale (red line) in Daejeon, Korea, and (b) overlap of OSM (black line) and Google Earth image).

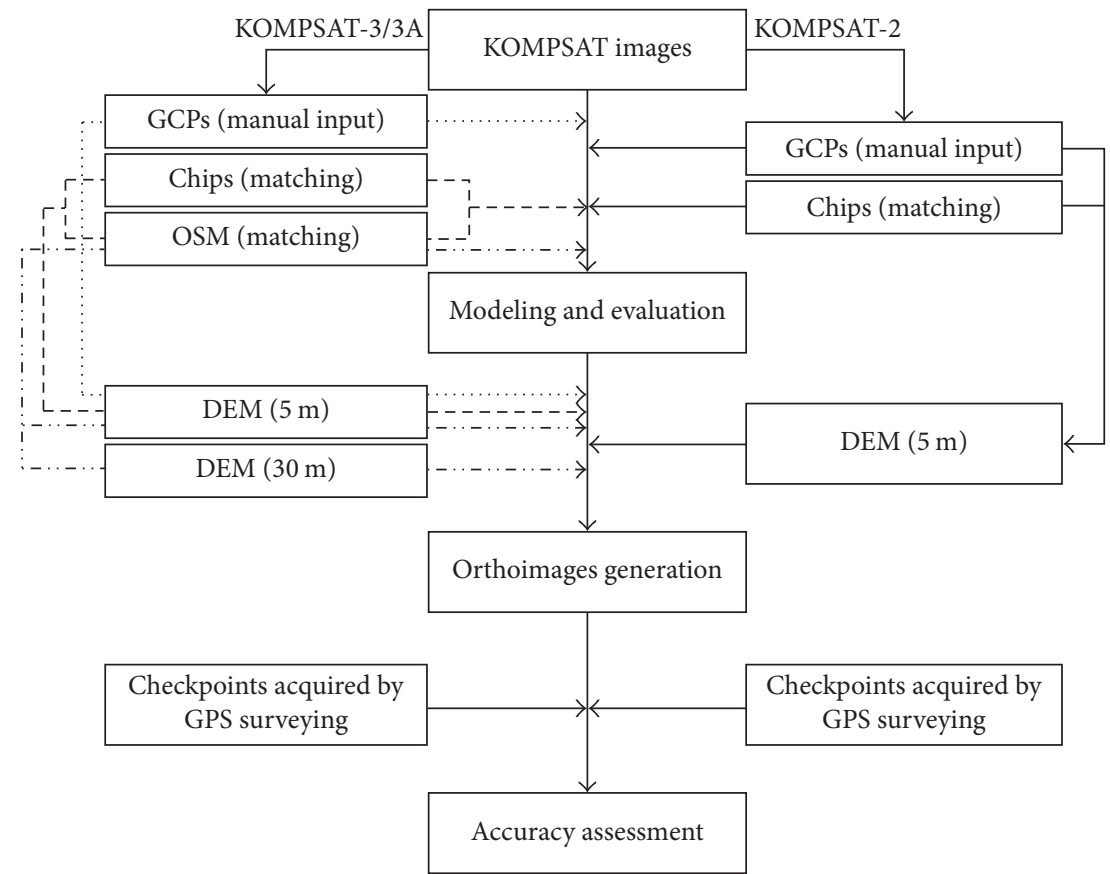

FIGURE 4: Flow chart of data processing experiment for orthorectification.

Figure 3, the OSM data provide only the centerlines of the roads, but they are well matched with the road centers of the existing digital map and the Google Earth image.

3.3. Data Processing. For many applications, location accuracy of satellite images is just as important as spatial resolution. However, in general, the RPCs provided with the satellite images do not meet the accuracy required by the user. Therefore, users have to improve this accuracy through additional processing using various reference data. For this study, orthorectification of KOMPSAT optical images was performed through the process shown in Figure 4.

This study is divided into two parts. First, orthorectification of KOMPSAT-2 images was performed using GCPs and $5 \mathrm{~m}$ DEM. The GCP input was registered in two ways. The GCPs extracted from the aerial orthophotos $(0.25 \mathrm{~m})$ were manually distributed evenly throughout the image (study area (a)), and the GCP chips were registered by the matching method (study area (b)). The second experiment used various control point sources, and DEM was performed to investigate the effect of ground reference data for orthorectifying submeter high resolution KOMPSAT images. For this purpose, orthorectification for KOMPSAT-3 and KOMPSAT$3 \mathrm{~A}$ images was carried out using relatively accurate reference data and well-known open source data (e.g., OSM and SRTM DEM) in study areas (c) and (d).

With the appearance of high resolution satellite images, image correction using RPCs has become common. For 
this study, geometric modeling was conducted based on the RPCs provided with the images. However, as mentioned earlier, the accuracy of RPCs should be improved. The RPCs may be refined directly or indirectly. Direct refinement methods modify the original RPCs themselves, while indirect refinement methods do not change the original RPCs. In general, direct refinement is the most widely used method. Direct refinement can be classified into bias compensation and the polynomial model. Previous studies have shown that the bias-compensation method has slightly better accuracy than the polynomial model [8]. In the case of KOMPSAT, many studies have been carried out to improve the position accuracy using the bias-compensation method $[11,19,20]$.

The RPC block adjustment model used in this study is defined in the image space. The model is defined as follows [4]:

$$
\begin{aligned}
\text { Line } & =\Delta p+p(\phi, \lambda, h)+\varepsilon_{L} \\
\text { Sample } & =\Delta r+r(\phi, \lambda, h)+\varepsilon_{s} .
\end{aligned}
$$

Line and Sample are the coordinates of the image point corresponding to the GCPs. $\Delta p$ and $\Delta r$ are the adjustable functions expressing the differences between the measured and the nominal line and the sample coordinates of the GCPs for an image. $p(\phi, \lambda, h)$ and $r(\phi, \lambda, h)$ are the image coordinates calculated using the provided RPCs. $\varepsilon_{L}$ and $\varepsilon_{s}$ are random unobservable errors.

$$
\begin{aligned}
\Delta p= & a_{0}+a_{S} \cdot \text { Sample }+a_{L} \cdot \text { Line }+a_{S L} \cdot \text { Sample } \cdot \text { Line } \\
& +a_{L 2} \cdot \text { Line }^{2}+a_{S 2} \cdot \text { Sample }^{2}+\cdots \\
\Delta r= & b_{0}+b_{S} \cdot \text { Sample }+b_{L} \cdot \text { Line }+b_{S L} \cdot \text { Sample } \cdot \text { Line } \\
& +b_{L 2} \cdot \text { Line }^{2}+b_{S 2} \cdot \text { Sample }^{2}+\cdots
\end{aligned}
$$

$a_{0}, a_{S}, a_{L}, \ldots$ and $b_{0}, b_{S}, b_{L}, \ldots$ are the adjustment parameters for the image. Some satellites may require affine transformation as follows:

$$
\begin{gathered}
\Delta p=a_{0}+a_{S} \cdot \text { Sample }+a_{L} \cdot \text { Line } \\
\Delta r=b_{0}+b_{S} \cdot \text { Sample }+b_{L} \cdot \text { Line } .
\end{gathered}
$$

Control points collection using GCP chips and OSM was carried out by the matching method. Many studies on automatic geometric correction have been based on matching methods. As a result, various algorithms for image-to-image and vector-to-image matching have been presented [20-23]. The well-known matching algorithms such as Normalized Cross Correlation (NCC) and Fast Fourier Transform (FFT) have already been applied to some image processing software. In this study, matching for automatic GCPs collection was performed using software which implemented the FFT phase matching method. The phase correlation function [24] is given by

$$
d=F^{-1}\left(e^{j \emptyset}\right)
$$

where $\emptyset=\emptyset_{1}-\emptyset_{2}$ and $F^{-1}()$ demotes the inverse Fourier transform. The function $e^{j \emptyset}$ thus represents the phase of the cross power spectrum. The spatial displacement between the two patches is derived by image matching based on phase correlation in the $2 \mathrm{D}$ Fourier transform domain. In the case of vector matching, the candidate GCPs are located at line vertices (e.g., intersections) and receive their ground coordinate.

Image fusion based on the High-Pass Filter Additive (HPFA) technique was applied in order to generate high resolution multispectral KOMPSAT images. In the beginning, HPFA was used to reduce data volume and increase the spatial resolution of Landsat image data, but later it was also used for image fusion [25]. First, we produced the highpass filtered image. A high-pass convolution filter kernel was created and used to filter the high resolution input data. The size of the high-pass kernel is a function of the relative input pixel sizes. An adequate kernel size is approximately twice the resolution ratio of the image pairs $[25,26]$. The next step was to add the HP filtered image to the multispectral image:

$$
\mathrm{HPF}_{\text {fusion }}=\mathrm{MS}_{\text {resampling }}+\left(\mathrm{PAN}_{\mathrm{HPF}} \times W\right) \text {, }
$$

where $\mathrm{HPF}_{\text {fusion }}$ is a fused high resolution multispectral image and $\mathrm{MS}_{\text {resampling }}$ is a low resolution multispectral image that was resampled to the pixel size of a high resolution panchromatic image. $\mathrm{PAN}_{\mathrm{HPF}}$ is the HP filtered panchromatic image. The weighting is determined as follows:

$$
W=\frac{\mathrm{SD}(\mathrm{MS})}{\mathrm{SD}\left(\mathrm{PAN}_{\mathrm{HPF}}\right)} \times M,
$$

where $W$ is the weighting multiplier for the HF filtered panchromatic image value and $\mathrm{SD}(\mathrm{MS})$ is the standard deviation of the low resolution multispectral band to which the $\mathrm{HP}$ filtered panchromatic image is being added. $\mathrm{SD}\left(\mathrm{PAN}_{\mathrm{HPF}}\right)$ is the standard deviation of the HP filtered panchromatic image. $M$ is a modulating factor to determine the crispness of the output image. We empirically adjusted the $M$ value to enhance the sharpness through the enhancement of the boundary of the image. A linear stretch was performed as the last step.

\section{Experiment Results and Discussion}

4.1. Orthorectification Results of KOMPSAT Images Using GCPs and GCP Chips. A data processing test was performed only on those fusion images that were processed with high resolution multispectral images by the HPFA method. In the case of study area 1, modeling for orthorectification was performed by block units rather than individual image units because there were many KOMPSAT- 2 image to process. The GCPs were distributed uniformly, with an average of 7 10 points per image. At least 6 points extracted from an aerial orthophoto with a spatial resolution of $0.25 \mathrm{~m}$ were used as Orthophoto Checkpoints (OCPs). The altitude $(z)$ values of GCPs and OCPs were extracted from the DEM $(5 \mathrm{~m})$ and used. Figure 5 shows the modeling results for 947 KOMPSAT2 images. Although there were some gross errors, overall modeling accuracy was good. The average RMSE of GCPs and OCPs was 1.31 pixels and 1.41 pixels, respectively. 


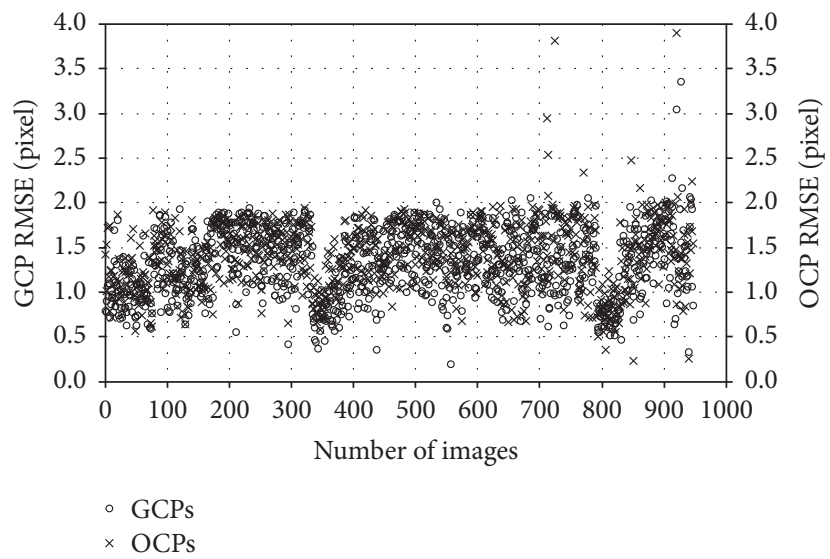

FIGURE 5: Modeling result of KOMPSAT-2 images using the GCP and OCPs.

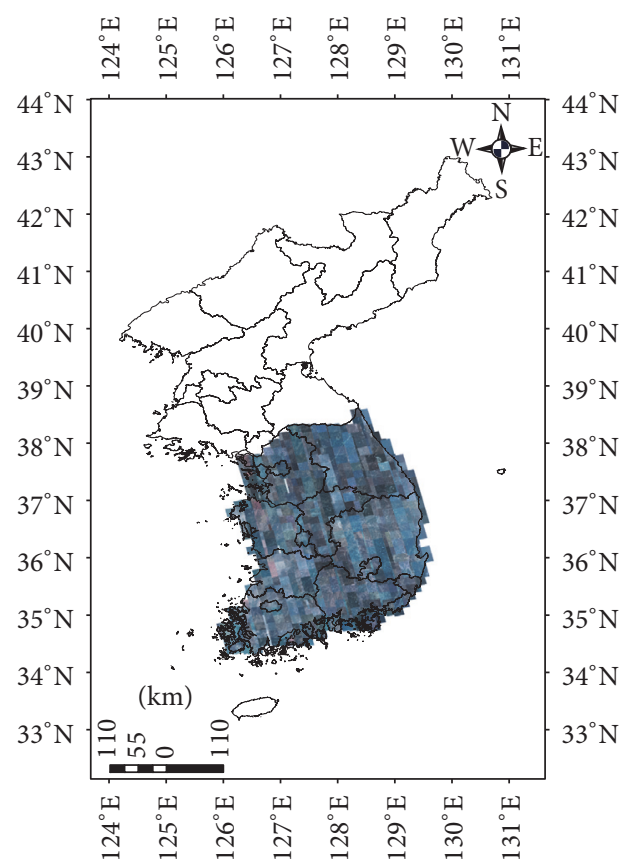

(a)

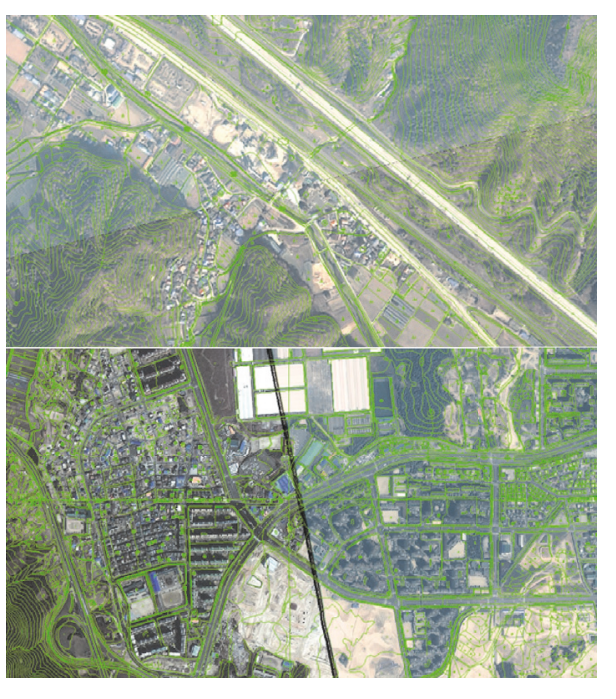

(b)

FIgURE 6: Generation of KOMPSAT-2 $1 \mathrm{~m}$ color orthoimages in study area 1 (a) and visual inspection using a digital topographic map of $1: 5000$ scale (b).

Based on the modeling results, KOMPSAT-2 orthoimages were generated using $5 \mathrm{~m}$ DEM as shown in Figure 6(a). We then overlaid the digital topographic map of 1:5000 scale on the generated orthoimages to visually inspect their qualities. Figure 6(b) shows the result of overlapping with the 1:5000scale digital topographic map for comparison of the accuracy between the left-right and top-bottom images. We found that the map layers were well matched with the orthoimages.

The accuracy of the generated orthoimages was evaluated using 843 Independent Checkpoints (ICPs) obtained by GPS surveying. Figure 7 shows the planimetric accuracy of KOMPSAT-2 $1 \mathrm{~m}$ color orthoimages generated in this study. Except for images with gross errors, the planimetric accuracy was $1.43 \mathrm{~m}$ (RMSE). As shown in Figure 7, the errors in the $x$ and $y$ directions were uniform and mostly within $\pm 3 \mathrm{~m}$.
Figure 8 shows the modeling results of 50 KOMPSAT-2 images in study area 2 using GCP chips. On average, about 52 GCPs were collected per image by chip matching. The average RMSE of the modeling result was 1.59 pixels. Most values were under 2 pixels, except for the mountain images where the values were slightly higher. Note that the modeling accuracy was lower than in the case of manually inputting GCPs as in study area 1.

The orthoimages generated using GCP chips and $5 \mathrm{~m}$ DEM are shown in Figure 9. For an accuracy assessment of generated orthoimages, 63 ICPs were used as shown in Figure 9(a). The errors in the $x$ and $y$ directions were very uniform and the planimetric accuracy was $1.40 \mathrm{~m}$ (RMSE). These results show that there is no significant difference with the accuracy of an orthoimage generated by manually 


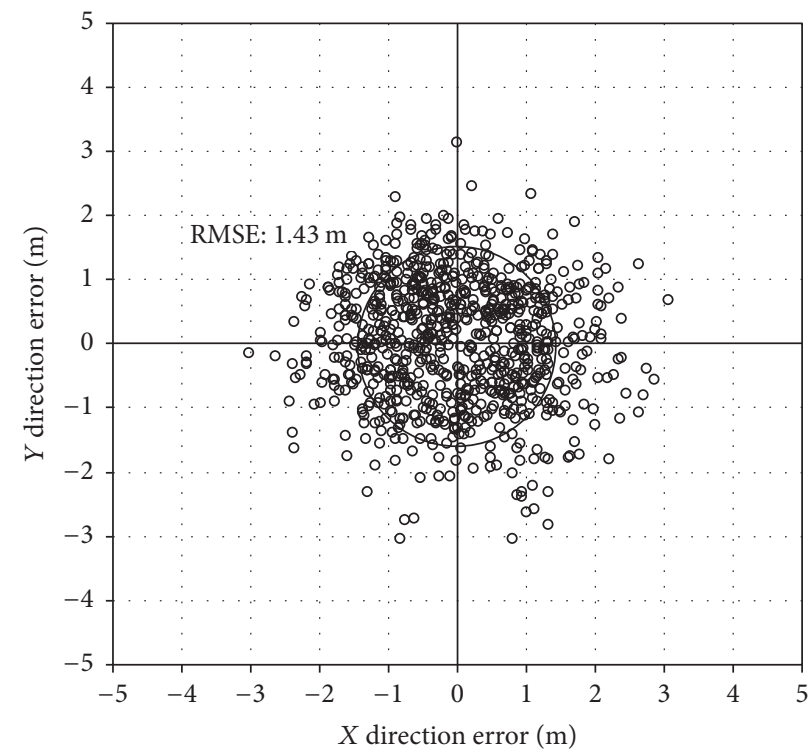

FIGURE 7: Scatter plot of planimetric errors in orthorectified KOMPSAT-2 image (1 m color) produced using GCPs and $5 \mathrm{~m}$ DEM.

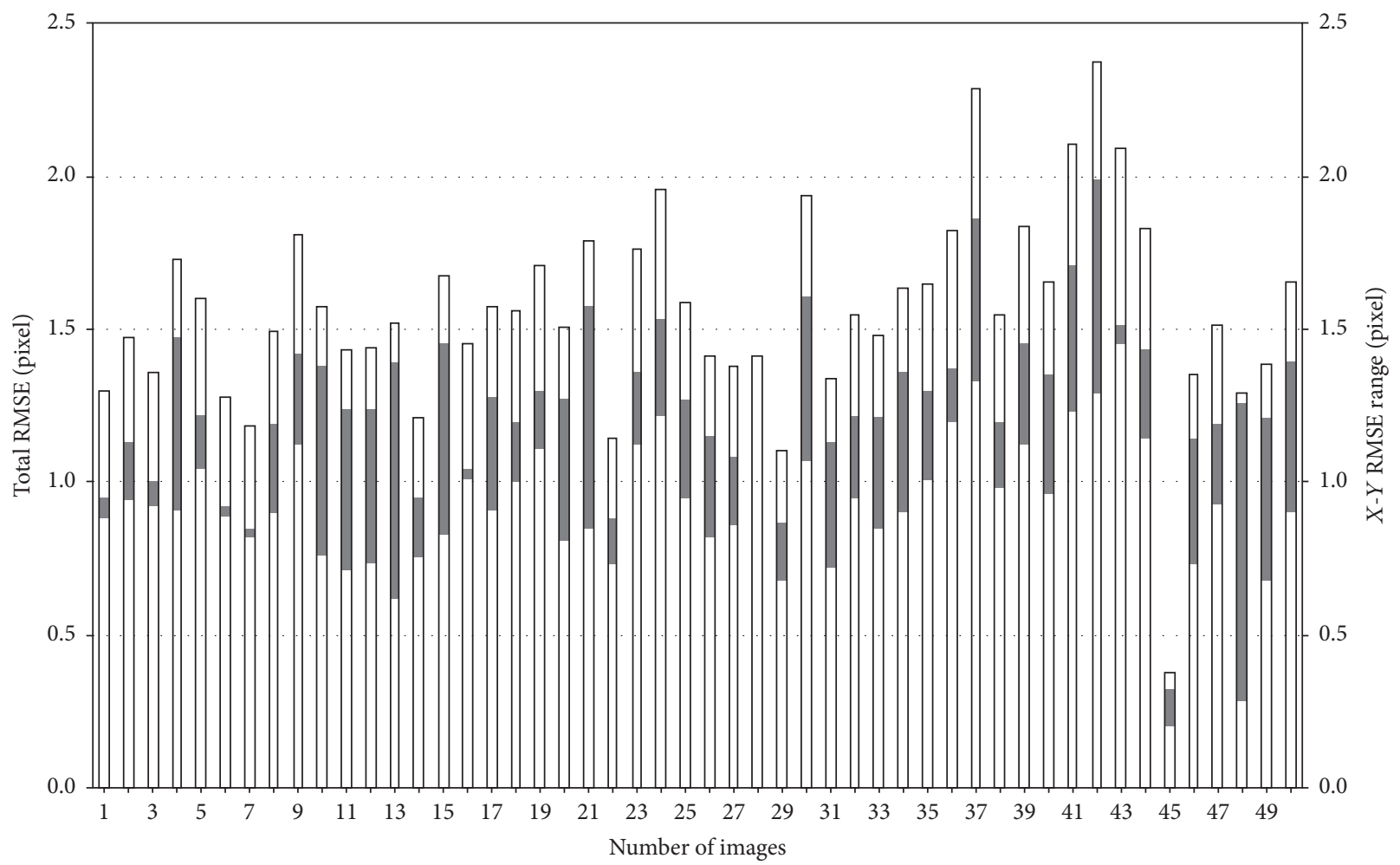

FIGURE 8: Modeling result of the 50 KOMPSAT-2 images using the GCP chips.

inputting GCPs in study area 1. However, as shown in Figure 9, sufficient ICPs could not be obtained so there was a limit to more accurate analysis.

To overcome this problem, additional accuracy analysis was performed using 190 OCPs which were extracted from aerial orthophotos $(0.25 \mathrm{~m})$. The maximum residuals were slightly higher than the previous results, but overall accuracy was very similar.
The same methods applied to KOMPSAT-2 for orthorectification. Image fusion was used to process KOMPSAT-3 and KOMPSAT-3A images in study area 3, and the results were analyzed. In order to model both KOMPSAT- 3 and KOMPSAT-3A images, 8 9 GCPs were used per image. About 24 control points per image were collected on average by chip matching. The average RMSE using GCPs in both KOMPSAT- 3 and KOMPSAT-3A images was less than 0.35 


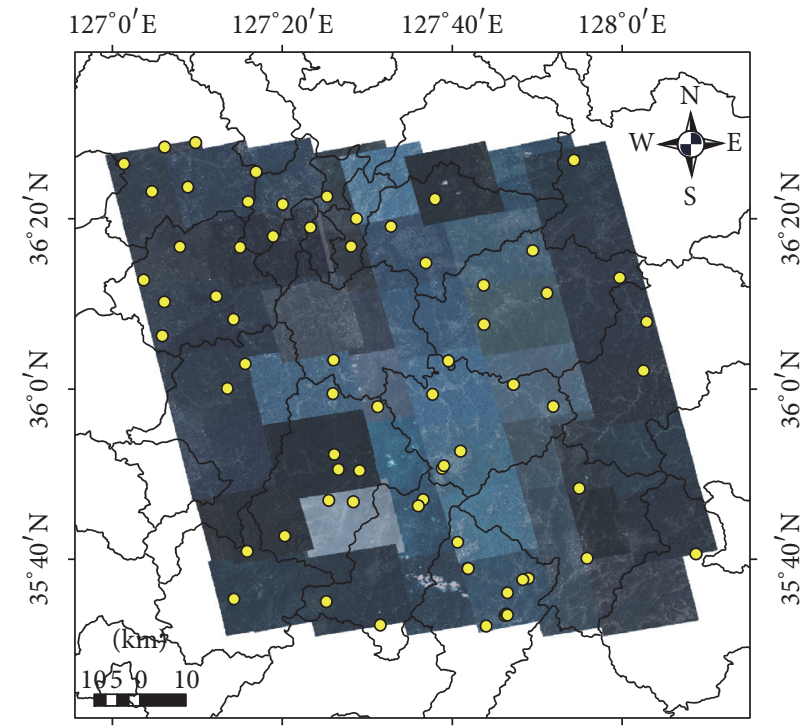

$127^{\circ} 0^{\prime} \mathrm{E}$ $127^{\circ} 20^{\prime} \mathrm{E}$ $127^{\circ} 40^{\prime} \mathrm{E}$

(a)

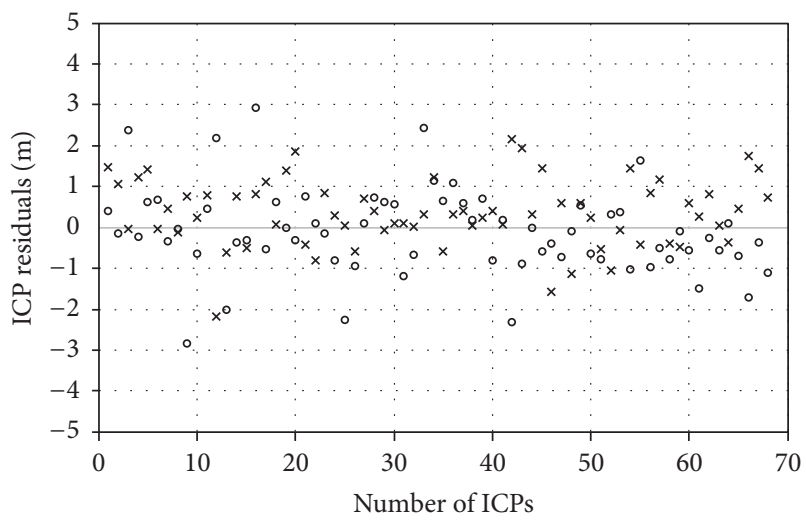

- DX

$\times$ DY

(b)

FIGURE 9: Distribution of ICPs in test area 2 (a) and scatter plot of planimetric errors in orthorectified KOMPSAT-2 image (1 m color) produced using GCP chips and $5 \mathrm{~m}$ DEM (b).

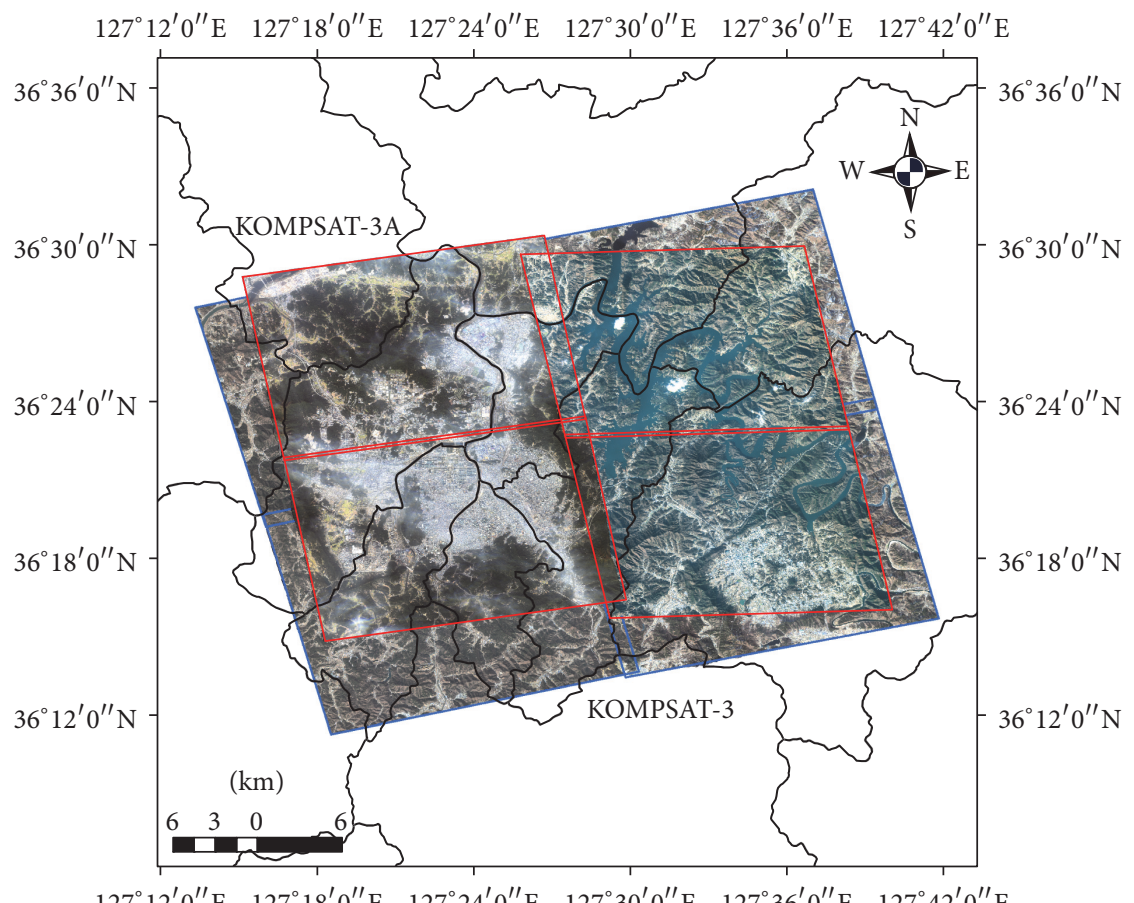

$127^{\circ} 12^{\prime} 0^{\prime \prime} \mathrm{E} \quad 127^{\circ} 18^{\prime} 0^{\prime \prime} \mathrm{E} \quad 127^{\circ} 24^{\prime} 0^{\prime \prime} \mathrm{E} \quad 127^{\circ} 30^{\prime} 0^{\prime \prime} \mathrm{E} \quad 127^{\circ} 36^{\prime} 0^{\prime \prime} \mathrm{E} \quad 127^{\circ} 42^{\prime} 0^{\prime \prime} \mathrm{E}$

FIgURE 10: Generation of KOMPSAT-3 ( $0.7 \mathrm{~m}$ color) and KOMPSAT-3A ( $0.55 \mathrm{~m}$ color) orthoimages using GCP chips and $5 \mathrm{~m}$ DEM in study area 3.

pixels, but in the case of using GCP chips, average RMSE was slightly larger than 2.0 pixels. The accuracy of orthoimages generated using $5 \mathrm{~m}$ DEM was analyzed using OCPs. As a result of analyzing the accuracy using about 18 point OCPs per image, it was confirmed that the GCP-based KOMPSAT3 and KOMPSAT-3A images had an accuracy of less than $1 \mathrm{~m}$, while GCP chip based orthorectified images had an planimetric accuracy on the order of $1.5 \mathrm{~m}$. Figure 10 shows the results of KOMPSAT-3 and KOMPSAT-3A orthoimage generation.

4.2. Orthorectification Results Based on Different Reference Data. In order to quantitatively evaluate the influence of the ground reference data in the submeter resolution satellite 


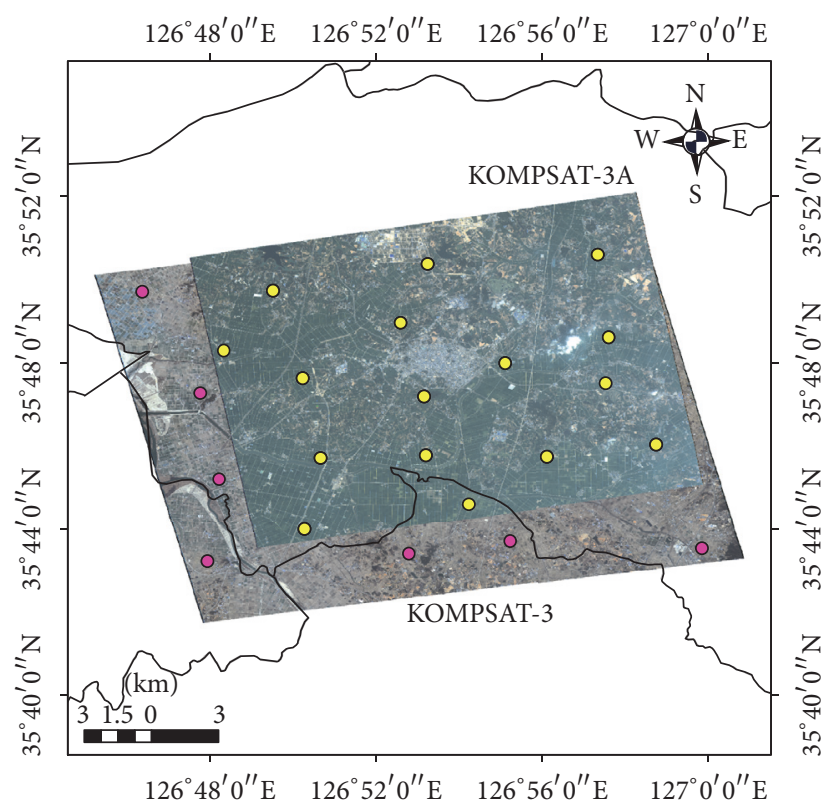

(a)

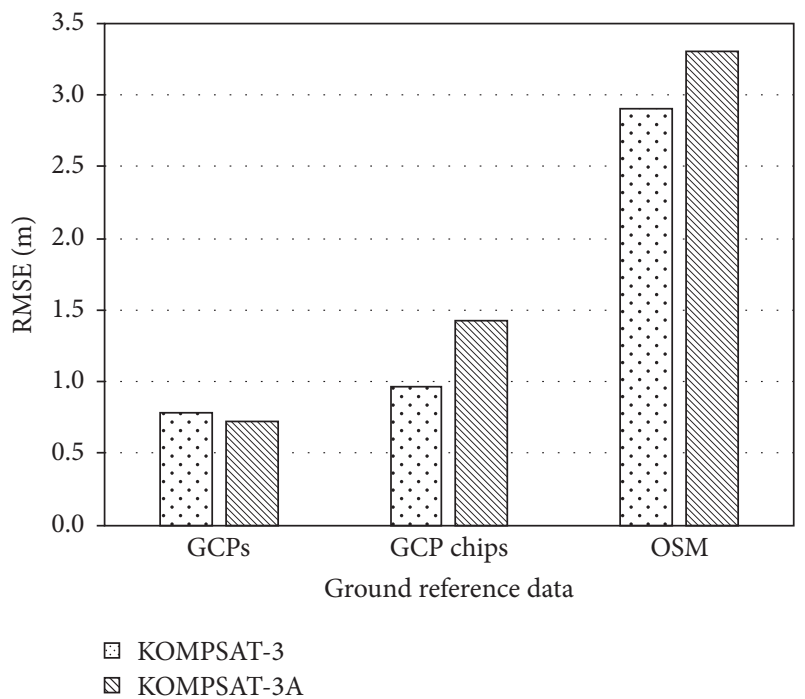

(b)

FIGURE 11: Distribution of the OCPs in study area 4 (a) and planimetric accuracy analysis results (b).

image correction, we performed orthorectification using KOMPSAT- 3 and KOMPSAT-3A images of study area 3 . The GCPs, GCP chips, and OSM were used for image modeling, and the modeling result of KOMPSAT- 3 and KOMPSAT-3A images using 9 and 11 GCPs was less than 0.4 pixels (RMSE). The modeling result using GCP chips had accuracy on the order of 2 pixels (RMSE). This result was found to be more accurate than OSM by 0.5 pixels. In addition, the number of control points collected through matching in both cases was about 50 . We generated KOMPSAT- 3 and KOMPSAT$3 \mathrm{~A}$ orthoimages using $5 \mathrm{~m}$ DEM as shown in Figure 11 and evaluated planimetric accuracy of the orthoimages using OCPs. In the case of OSM, modeling accuracy was similar to the result of using GCP chips, but the orthoimage accuracy was the lowest in the accuracy evaluation using OCPs. Figure 12 shows the results of overlaying an orthoimage generated using OSM and OSM data for evaluating accuracy by visual inspection. It was not easy to differentiate between the two datasets through visual inspection.

We performed additional experiments by crossing the data. Table 2 shows the data used in each case for the generation of KOMPSAT-3 orthoimages in study area 3. Experiments were carried out to evaluate orthoimage accuracy according to the horizontal and vertical data. Case 1 was aimed at analyzing the accuracy of the orthoimages according to control point $(x, y)$ quality. Case 2 was used to analyze the effect of DEMs.

First, modeling accuracy for Case 1 GCP chips and OSM was 2.33 pixels and 2.54 pixels, respectively. The accuracy of the generated orthoimages was analyzed using 29 OCPs, and it was $1.27 \mathrm{~m}$ and $2.54 \mathrm{~m}$, respectively. On the other hand, in Case 2 using different DEMs, the modeling accuracy was the same at 2.64 pixels. The planimetric accuracy of the
TABLE 2: Experiment of data processing using different datasets.

\begin{tabular}{lcc}
\hline Case & Horizontal data & Vertical data \\
\hline 1 & GCP chips & DEM $(5 \mathrm{~m})$ \\
2 & OSM & DEM $(5 \mathrm{~m})$ \\
& OSM & SRTM DEM $(30 \mathrm{~m})$ \\
\hline
\end{tabular}

orthoimages was $2.54 \mathrm{~m}$ for $5 \mathrm{~m}$ DEM and $2.91 \mathrm{~m}$ for $30 \mathrm{~m}$ DEM. In the case of $30 \mathrm{~m}$ DEM, the accuracy difference for a flat area was not large compared to $5 \mathrm{~m} \mathrm{DEM}$, but a difference of $5 \sim 6 \mathrm{~m}$ was found to occur for mountainous terrain. Figure 13 shows the planimetric accuracy analysis results on Case 1 and Case 2.

Figure 14 compares the accuracy of orthoimages according to the data used. It was easy to identify differences in each case with visual inspection. In Figure 14, (b) is the most accurate compared to the aerial orthophotos (a), and (d) is the least accurate. However, although the accuracy of the orthoimage using open data (e.g., OSM and SRTM DEM) is low in Figures 13 and 14, it can be seen that the location accuracy can be greatly improved when compared to the uncorrected image in Figure 15. Because open data can be obtained and used by anyone, it is possible to easily improve the location accuracy of the existing image through a simple image matching method.

\section{Conclusion}

In many applications, the location accuracy of satellite images is as important as the spatial resolution. However, few satellites possess the accuracy required by users, so additional 


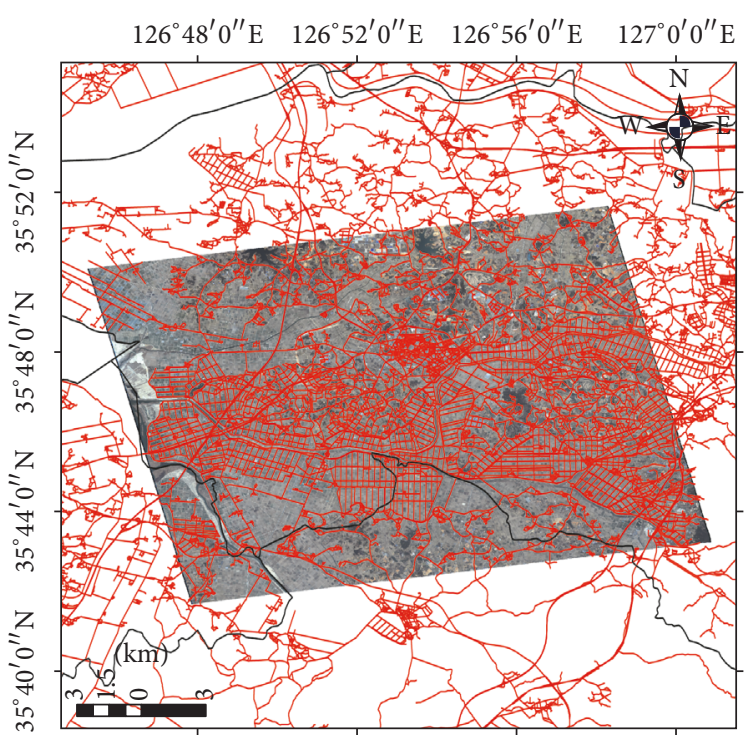

$126^{\circ} 48^{\prime} 0^{\prime \prime} \mathrm{E} \quad 126^{\circ} 52^{\prime} 0^{\prime \prime} \mathrm{E} \quad 126^{\circ} 56^{\prime} 0^{\prime \prime} \mathrm{E} \quad 127^{\circ} 0^{\prime} 0^{\prime \prime} \mathrm{E}$

(a) KOMPSAT- 3 orthoimage with OSM

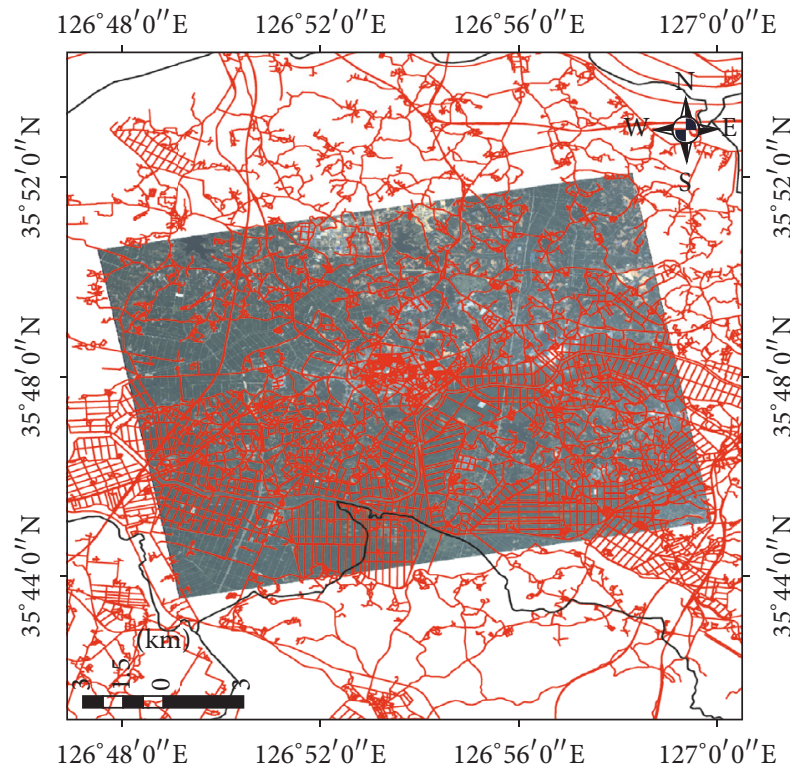

(c) KOMPSAT-3A orthoimage with OSM

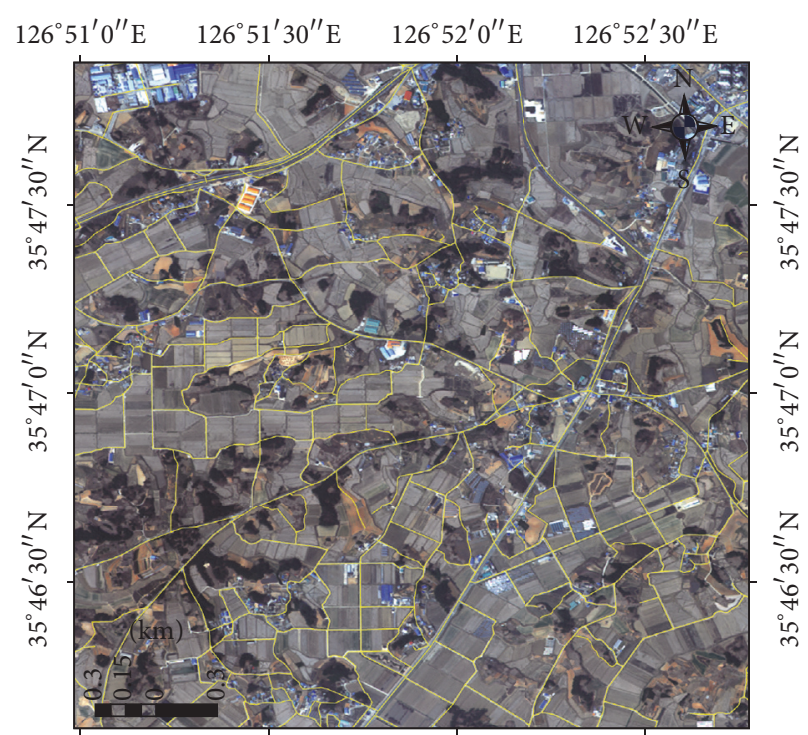

$126^{\circ} 51^{\prime} 0^{\prime \prime} \mathrm{E} \quad 126^{\circ} 51^{\prime} 30^{\prime \prime} \mathrm{E} \quad 126^{\circ} 52^{\prime} 0^{\prime \prime} \mathrm{E} \quad 126^{\circ} 52^{\prime} 30^{\prime \prime} \mathrm{E}$

(b) KOMPSAT-3 zoom-in image

$126^{\circ} 51^{\prime} 0^{\prime \prime} \mathrm{E} \quad 126^{\circ} 51^{\prime} 30^{\prime \prime} \mathrm{E} \quad 126^{\circ} 52^{\prime} 0^{\prime \prime} \mathrm{E} \quad 126^{\circ} 52^{\prime} 30^{\prime \prime} \mathrm{E}$

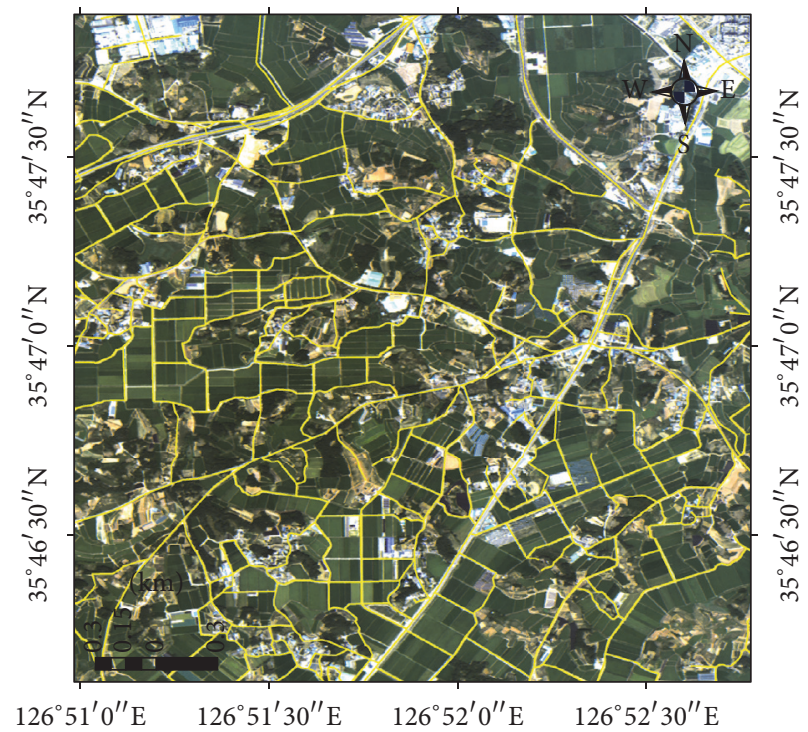

(d) KOMPSAT-3A zoom-in image

FIGURE 12: Overlap of KOMPSAT orthoimages and OSM data $(a, c)$ and visual inspection using zoom-in images (b, d).

processing is necessary. To improve the location accuracy of high resolution satellite images, a lot of time and money are often required for control points, DEM, and the like. Also, high quality ground reference data are not always available. In order to utilize KOMPSAT optical images for applications such as GIS, it is necessary to orthorectify the images. Therefore, for this study and with updated RPCs, we performed orthorectification of KOMPSAT images using various data and evaluated the results. The planimetric accuracy of KOMPSAT-2 orthoimages generated from GCPs with horizontal and vertical accuracies of $1 \mathrm{~m}$ (RMSE) and $2 \mathrm{~m}$ (RMSE), respectively, was the best. However, the orthoimages generated through matching with the existing corrected images such as GCP chips also had sufficient accuracy. We also found that the planimetric accuracy of the KOMPSAT-3 and KOMPSAT-3A orthoimages generated using GCPs and GCP chips was $1 \mathrm{~m}$ (RMSE) and $15 \mathrm{~m}$ (RMSE), respectively. Although good quality GCPs and DEM have a great influence on orthoimage generation, it is not always possible to obtain high quality datasets, and so orthorectification was performed using OSM and SRTM DEM $(30 \mathrm{~m})$ in this study. We analyzed the availability of open source data for image correction, even though the location accuracy was poor compared to GCPs and GCP chips. The orthoimages generated using OSM and $30 \mathrm{~m}$ DEM had accuracy on the order of $3 \mathrm{~m}$ (RMSE). However, in mountainous terrain it was 


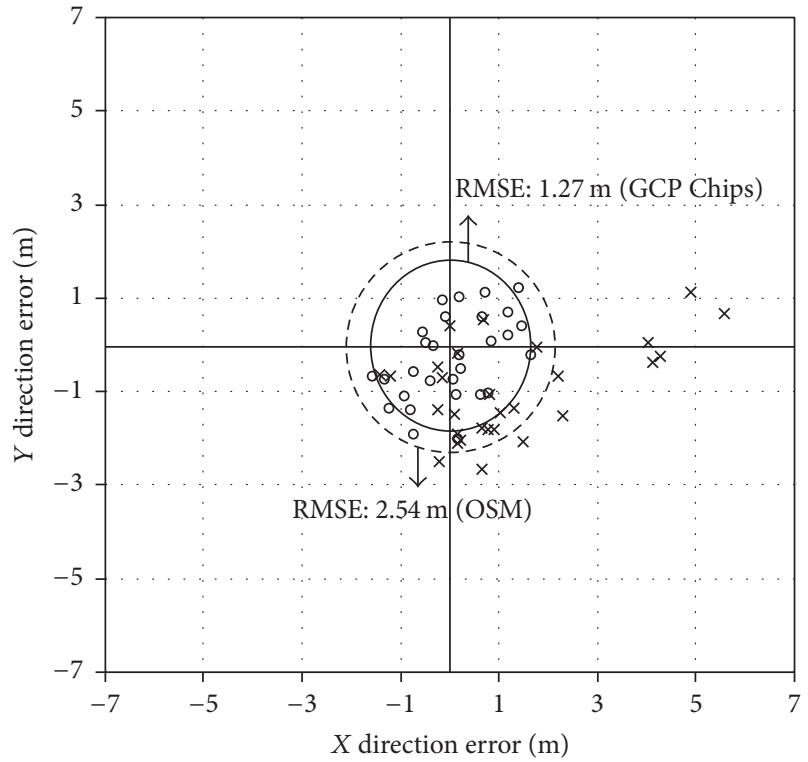

- GCP chips with DEM (5 m)

$\times$ OSM with DEM $(5 \mathrm{~m})$

(a)

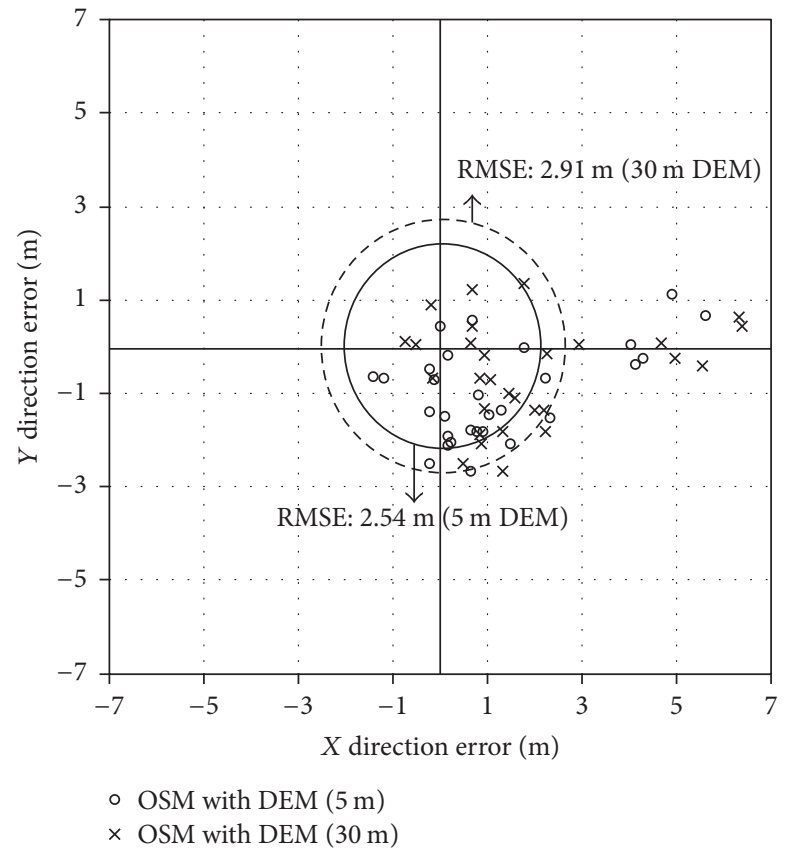

(b)

Figure 13: Results of planimetric accuracy analysis on Case 1 (a) and Case 2 (b).

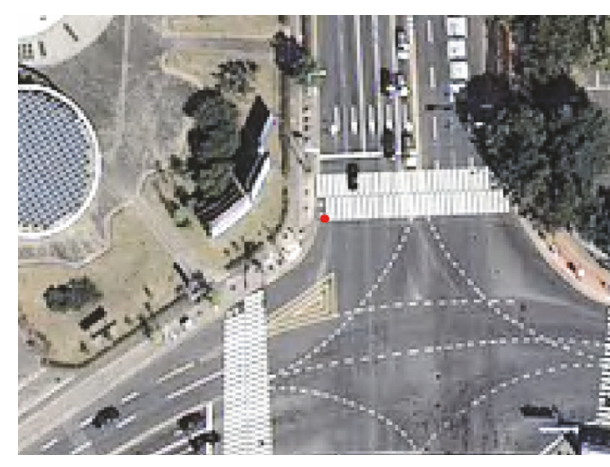

(a) Aerial orthophoto

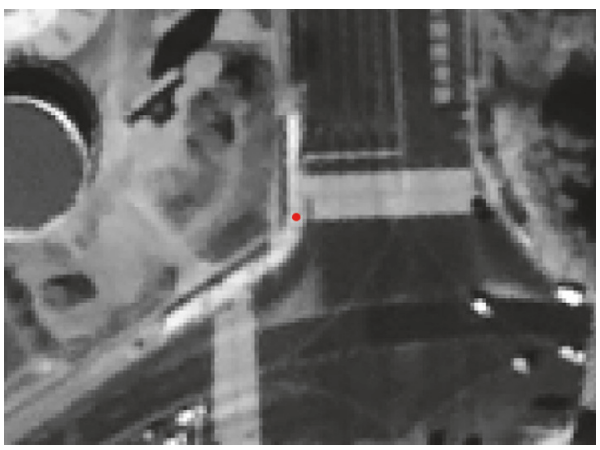

(c) OSM with $5 \mathrm{~m}$ DEM

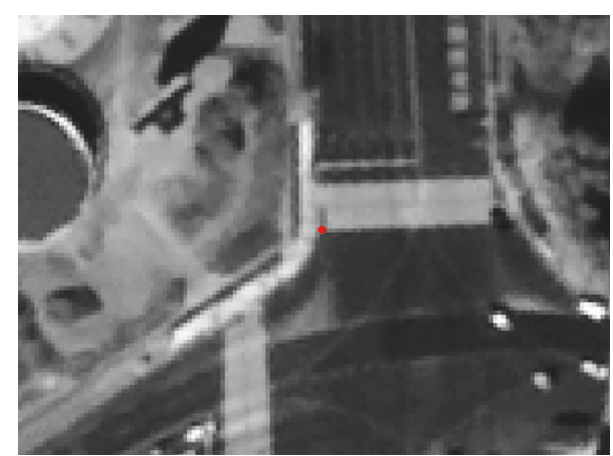

(b) Chip with $5 \mathrm{~m}$ DEM

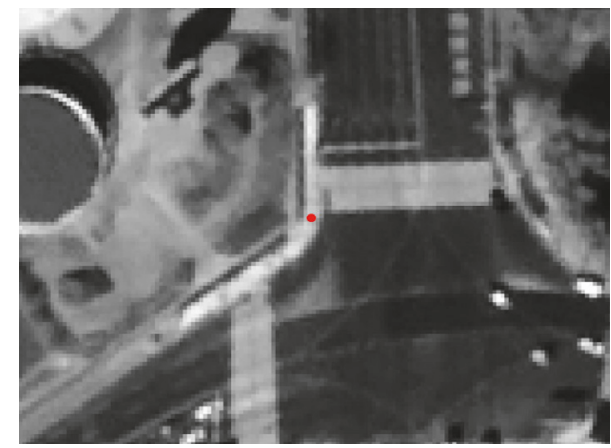

(d) OSM with $30 \mathrm{~m}$ DEM

FIGURE 14: Comparison of orthoimage accuracy according to the used data. 


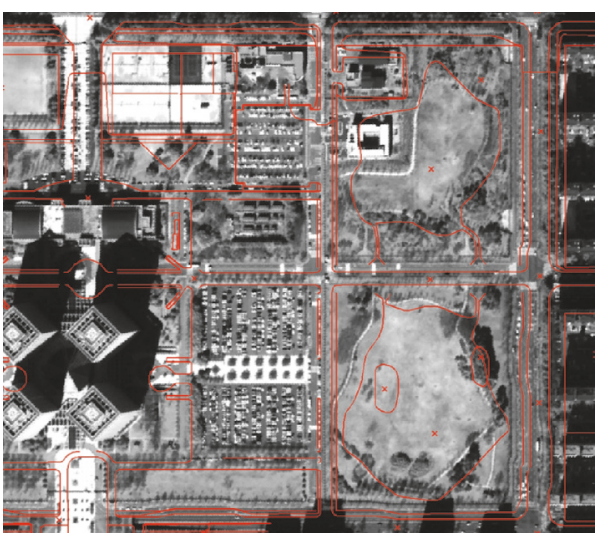

(a)

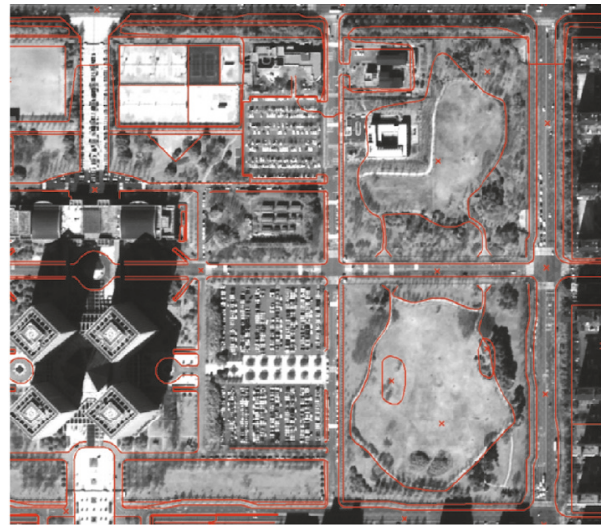

(b)

FIGURE 15: Comparison of planimetric accuracy using a digital topographic map of 1:5000 scale ((a) KOMPSAT-3 uncorrected image and (b) KOMPSAT-3 orthoimage generated using OSM and $30 \mathrm{~m}$ DEM).

found to have a maximum error of about $6 \mathrm{~m}$ (RMSE). In the future, we will present a more efficient correction method for KOMPSAT images using improved image matching techniques and a greater variety of data.

\section{Conflicts of Interest}

The authors declare that there are no conflicts of interest regarding the publication of this paper.

\section{References}

[1] E. Kruck, "Photogrammetric mapping of SPOT images with BINGO in the PHOCUS system," International Achieves of Photogrammetry and Remote Sensing (Commission III), vol. 27, no. B3, pp. 405-414, 1988.

[2] C. V. Tao and Y. Hu, "A comprehensive study of the rational function model for photogrammetric processing," Photogrammetric Engineering and Remote Sensing, vol. 67, no. 12, pp. 13471357, 2001.

[3] C. S. Fraser and H. B. Hanley, "Bias compensation in rational functions for Ikonos satellite imagery," Photogrammetric Engineering and Remote Sensing, vol. 69, no. 1, pp. 53-57, 2003.

[4] J. Grodecki and G. Dial, "Block adjustment of high-resolution satellite images described by Rational Polynomials," Photogrammetric Engineering and Remote Sensing, vol. 69, no. 1, pp. 59-68, 2003.

[5] K. Di, R. Ma, and R. X. Li, "Rational functions and potential for rigorous sensor model recovery," Photogrammetric Engineering and Remote Sensing, vol. 69, no. 1, pp. 33-41, 2003.

[6] C. V. Tao, Y. Hu, and W. Jiang, "Photogrammetric exploitation of IKONOS imagery for mapping applications," International Journal of Remote Sensing, vol. 25, no. 14, pp. 2833-2853, 2004.

[7] J. Wang, K. Di, and R. Li, "Evaluation and improvement of geopositioning accuracy of IKONOS stereo imagery," Journal of Surveying Engineering, vol. 131, no. 2, pp. 35-42, 2005.

[8] Z. Xiong and Y. Zhang, "A generic method for RPC refinement using ground control information," Photogrammetric Engineering and Remote Sensing, vol. 75, no. 9, pp. 1083-1092, 2009.

[9] D. Seo, J. Yang, D. Lee, and H. Lim, "The analysis for KOMPSAT-2 mapping accuracy characteristics," in Proceedings of the 60th International Astronautical Congress, IAC-09.B1.I.13, pp. 1-10, Daejeon, Republic of Korea, October 2009.

[10] S. Sunier, B. Collet, and A. Mambimba, "New third party mission, quality assessment: KOMPSAT-2 mission," GAEL Consultant, pp. 1-20, 2008.

[11] J. K. Nowak Da, Costa., and A. Walczynska, "Geometric quality testing of the kompsat-2 image data acquired over the JRC maussane test site using ERDAS LPS and PCI GEOMATICS remote sensing software," JRC Scientific and Technical Reports (EUR 24542 EN), pp. 1-36, 2010.

[12] SI Imaging Services Co., LTD, "KOMPST-3A product specifications: image data manual (version 1.0)," pp. 1-51, 2016.

[13] SI. Imaging and Co. SI Imaging Services, "KOMPST-3 product specifications: image data manual (version 2.0)," pp. 1-59, 2017.

[14] D. Seo, J. Oh, C. Lee, D. Lee, and H. Choi, "Geometric calibration and validation of Kompsat-3A AEISS-A camera," Sensors (Switzerland), vol. 16, no. 10, article no. 1776, 2016.

[15] H. Lee, J. Ru, and Y. Yu, "Extracting high quality thematic information by using high-resolution satellite imagery," Journal of the Korean Society for Geospatial Information Science, vol. 18, no. 1, pp. 73-91, 2010.

[16] G. Sun, K. J. Ranson, V. I. Kharuk, and K. Kovacs, "Validation of surface height from shuttle radar topography mission using shuttle laser altimeter," Remote Sensing of Environment, vol. 88, no. 4, pp. 401-411, 2003.

[17] J. R. Santillan and M. Makinano-Santillan, "Vertical accuracy assessment of 30-M resolution ALOS, ASTER, and SRTM global DEMS over Northeastern Mindanao, Philippines," in Proceedings of the 23rd International Archives of the Photogrammetry, Remote Sensing and Spatial Information Sciences Congress, ISPRS 2016, pp. 149-156, cze, July 2016.

[18] H. G. Park, "Study on the Korean accuracy standards setting of digital map for the construction and utilization of precise geospatial information," Journal of the Korean Society of Surveying Geodesy Photogrammetry and Cartography, vol. 31, no. 6, pp. 493-502, 2013.

[19] J. Oh and C. Lee, "Automated bias-compensation of rational polynomial coefficients of high resolution satellite imagery based on topographic maps," ISPRS Journal of Photogrammetry and Remote Sensing, vol. 100, pp. 14-22, 2015. 
[20] J. H. Oh, D. C. Seo, and C. N. Lee, "A test result on the positional accuracy of Kompsat-3A beta test images," Journal of the Korean Society of Surveying, Geodesy, Photogrammetry and Cartography, vol. 34, no. 2, pp. 133-142, 2016.

[21] P. Pehani, K. Čotar, A. Marsetič, J. Zaletelj, and K. Oštir, "Automatic geometric processing for very high resolution optical satellite data based on vector roads and orthophotos," Remote Sensing, vol. 8, no. 4, article no. 343, 2016.

[22] M. Gianinetto and M. Scaioni, "Automated geometric correction of high-resolution pushbroom satellite data," Photogrammetric Engineering and Remote Sensing, vol. 74, no. 1, pp. 107116, 2008.

[23] S. Leprince, S. Barbot, F. Ayoub, and J.-P. Avouac, "Automatic and precise orthorectification, coregistration, and subpixel correlation of satellite images, application to ground deformation measurements," IEEE Transactions on Geoscience and Remote Sensing, vol. 45, no. 6, pp. 1529-1558, 2007.

[24] C. D. Kuglin and D. C. Hines, "The phase correlation image alignment method," in Proceedings of the in proceeding of International Conference on Cybernetics Society, pp. 163-165, 1975.

[25] U. G. Gangkofner, P. S. Pradhan, and D. W. Holcomb, "Optimizing the high-pass filter addition technique for image fusion," Photogrammetric Engineering and Remote Sensing, vol. 74, no. 9, pp. 1107-1118, 2008.

[26] P. S. Chavez Jr., S. C. Sides, and J. A. Anderson, "Comparison of three different methods to merge multiresolution and multispectral data. Landsat TM and SPOT panchromatic," Photogrammetric Engineering and Remote Sensing, vol. 57, no. 3, pp. 295-303, 1991. 


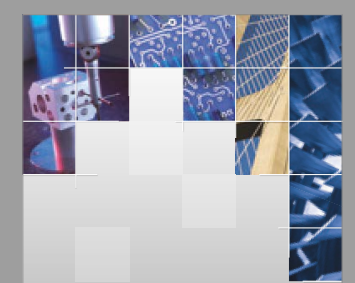

\section{Enfincering}
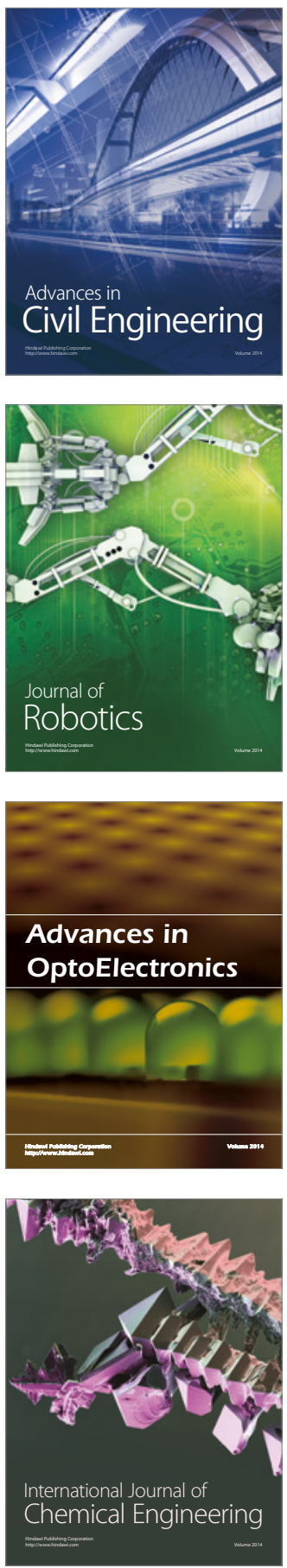

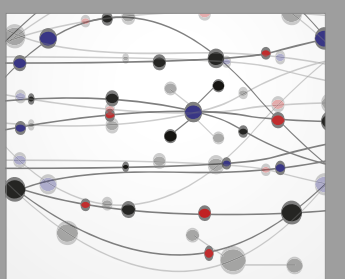

The Scientific World Journal

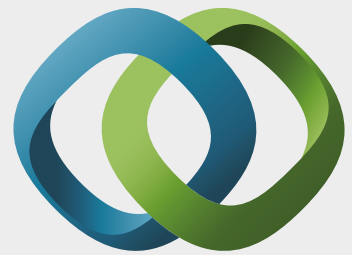

\section{Hindawi}

Submit your manuscripts at

https://www.hindawi.com
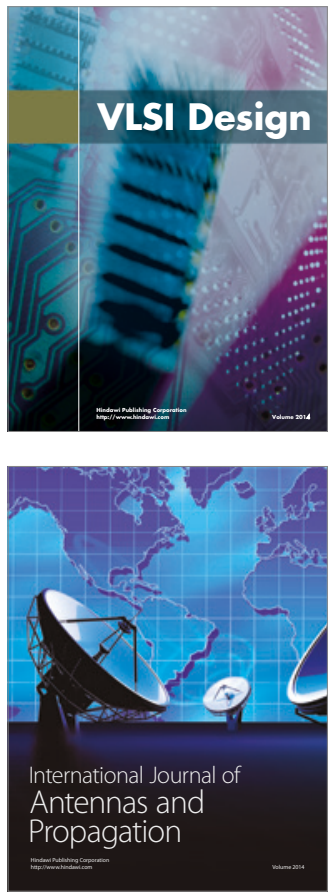

\section{Rotating}

Machinery
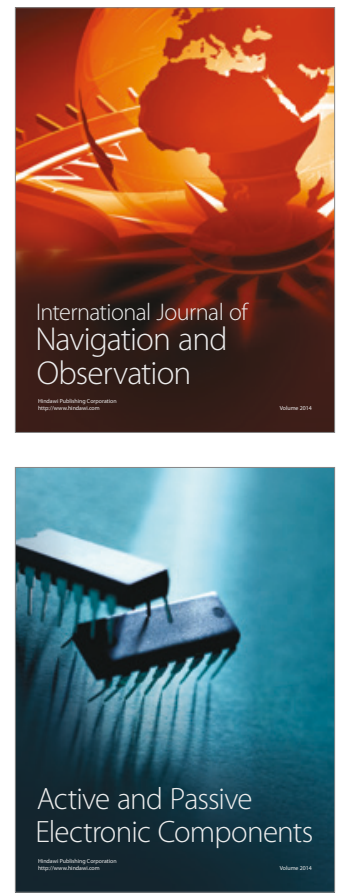
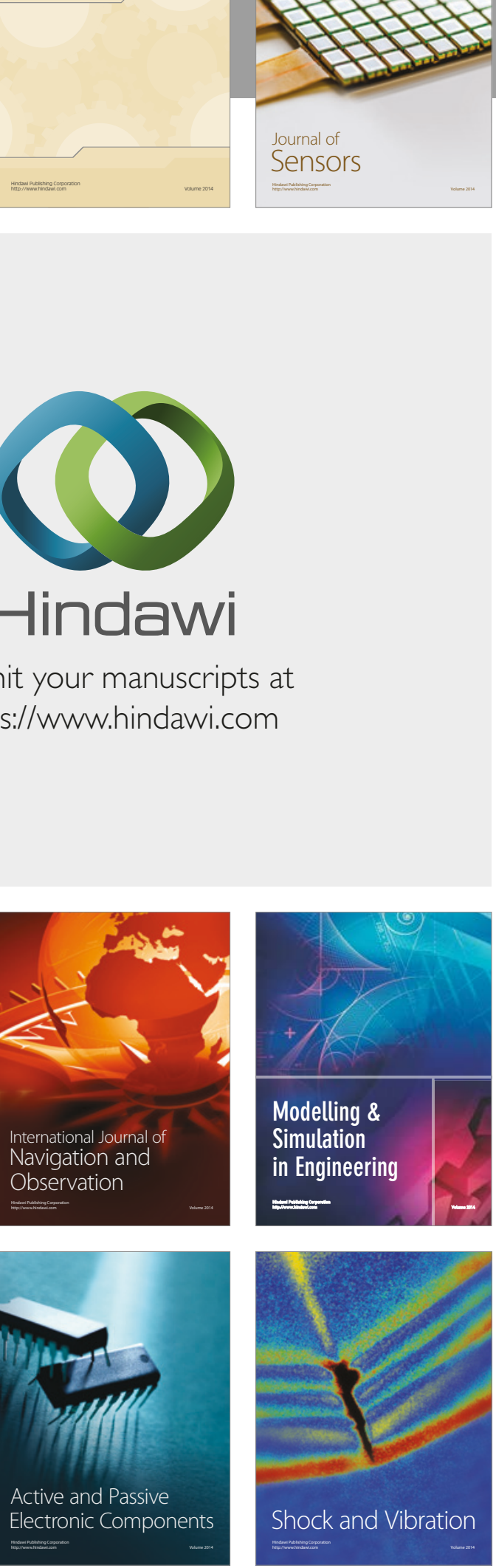
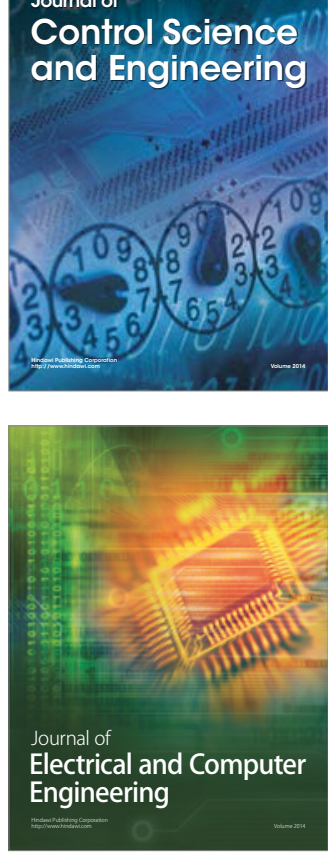

Distributed

Journal of

Control Science

and Engineering
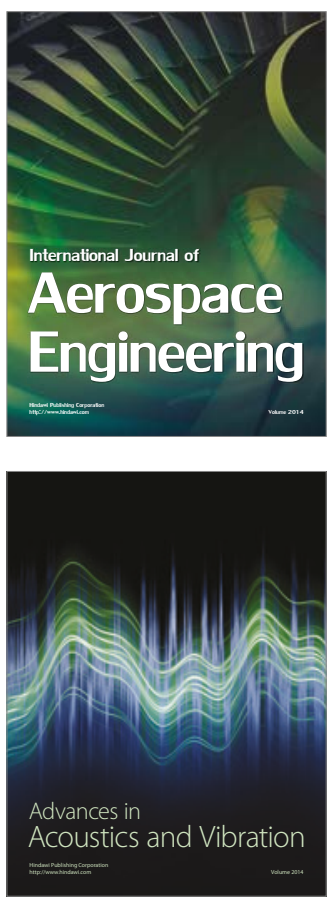

Sensor Networks 